\title{
THE PRECIPITABLE IODINE OF SERUM IN NORMAL PREG- NANCY AND ITS RELATION TO ABORTIONS ${ }^{1}$
}

\author{
BY EVELYN B. MAN, MARTIN HEINEMANN, CARL E. JOHNSON, DEBORAH C. \\ LEARY, AND JOHN P. PETERS \\ (From the Departments of Medicine and Obstetrics, Yale University School of Medicine,
New Haven, Conn.)
}

(Submitted for publication August 2, 1950; accepted, November 6, 1950)

In 1948 it was reported by Heinemann, Johnson and Man (1) that early in pregnancy the precipitable (protein-bound) iodine in the serum (SPI) rose to concentrations in the upper range of normal or even to levels that outside of pregnancy are characteristic of hyperthyroidism. It also appeared that if the SPI did not rise, the pregnancy was likely to end in abortion within the first four months. Some evidence was presented that such accidents might be prevented by the administration of active thyroid substance. The present paper deals with a further investigation of the phenomenon.

\section{MATERIAL}

Patients from the Clinics of the Department of Obstetrics and Gynecology in the New Haven Hospital form part of the material studied. In addition, analyses of the serum of patients have been made for members of the Clinical Faculty who have permitted the data to be used and have generously contributed the clinical information required for the purposes of this investigation. Finally, a certain number of patients with disorders of function of the thyroid were drawn from the Metabolism Clinic.

In many cases only single observations are available. In some, determinations of SPI were made at intervals throughout pregnancy. In a limited number observations were continued into the early postpartum period. For obvious reasons, figures preceding pregnancy were only occasionally obtained. In a certain proportion of cases serum lipids were also measured.

\section{METHODS}

Venous blood was drawn, with precautions against contamination by iodine, from patients in the postabsorptive state or after a meal free from fat (fruit juice, black coffee, and toast, either dry or with jam). Serum was removed under anaerobic precautions. Lipids were measured by the method of $\mathrm{Man}$ and her associates (2-6). Until July, 1949, SPI was measured by the

1 This investigation was supported (in part) by a research grant from the U. S. Public Health Service. method of Riggs and Man (7); after that date by a micromodification (8). Analytical results by the two methods agree.

\section{RESULTS}

Normal pregnancy. In Figure 1 are presented the values for SPI obtained on one or more occasions from 46 normal women during the course of pregnancies that proceeded to term without complications. None of these patients received thyroid or any medication known to affect thyroid function during their pregnancies or in the periods immediately preceding or following pregnancy. Four had goiters without evidence of abnormal activity of the thyroid. Of the 56 determinations from the end of 16 weeks until term, SPI was only twice lower than $5.6 \gamma$ per cent, and in all but three instances was $6.0 \gamma$ per cent or higher. Values lower than $6.0 \gamma$ per cent were only transitory incidents. The average concentration of SPI in nonpregnant normal persons is $5.0 \gamma$ per cent (8). In the last 24 weeks of normal pregnancy, therefore, SPI was invariably above the average normal value for nonpregnant persons. It is not uncommon to find values up to $10 \gamma$ per cent which, outside of pregnancy, would denote severe hyperthyroidism. In pregnancy, however, such concentrations are associated with no symptoms, signs, nor metabolic disorders indicative of overactivity of the thyroid gland.

In the same figure is illustrated the course of SPI in the progress of pregnancy in a series of patients in whom repeated observations were made. There is no definite tendency for SPI to rise or fall during the last 24 weeks. It is, however, subject to fluctuations far greater than those that have been observed in nonpregnant individuals. Variations of $2 \gamma$ per cent over relatively short intervals are frequent and variations of as much as $4 \gamma$ per cent have been encountered, with- 


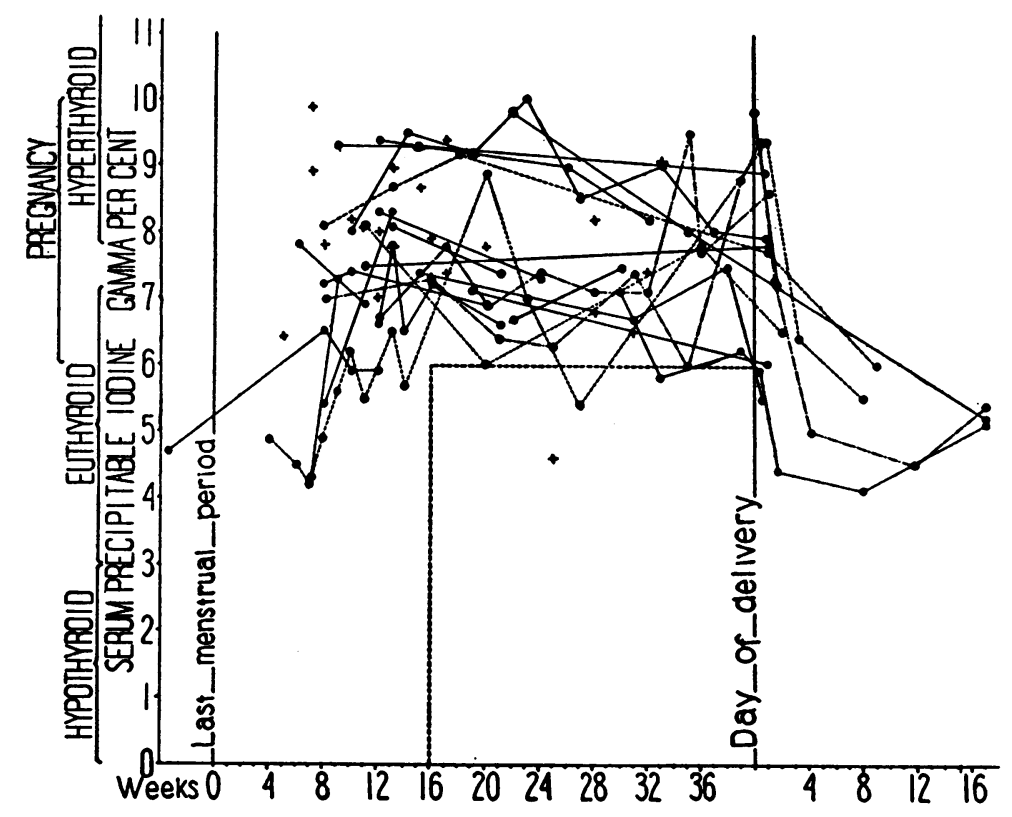

Fig. 1. Serum Precipitable Iodine (SPI) in the Course of Normal PREgnANCY

Crosses represent single observations. Circles connected by lines represent repeated observations.

out any discernible disturbances. In normal individuals SPI is quite stable $(8,9)$.

In many or most instances the SPI rises sharply at or near the onset of pregnancy. Concentrations in the hyperthyroid range have been obtained as early as six weeks after the last menstrual period. In only one case was an observation obtained preceding pregnancy. In this case SPI had risen from 4.7 to $6.5 \gamma$ per cent by the time the first measurement in pregnancy was taken, eight weeks after the last mentrual period. In a certain proportion of subjects, however, the rise is distinctly delayed; and in most it continues after the initial sharp increase. The same large fluctuations observed during the later part of pregnancy are evident in these early stages. Sometimes, as a result of these fluctuations, SPI, after the initial rise, drops down again temporarily into the nonpregnant range.

After delivery SPI diminished again, returning to normal nonpregnant values. The consistency of this fall, like that of the initial rise, indicates quite clearly that the elevation of SPI during pregnancy is a feature characteristic of pregnancy, not of the subjects of this particular study. The data are too scanty to permit precise definition of the course of the decline. Occasionally it was quite precipitate. In most instances it did not become evident until the second week postpartum, or even later. At first it was rapid, thereafter continuing, sometimes for a period of several weeks, at a more gradual rate. The possibility that these variations may be related to lactation deserves inquiry. When the decline was delayed, signs of overactivity of the thyroid remained in abeyance. The tolerance to high SPI appears to persist for an appreciable interval after the termination of pregnancy.

In addition to the subjects of Figure 1, 14 apparently normal women are still undelivered at the present date. Table I shows the duration of pregnancy to date in each case, the SPI values and the duration of the pregnancy at the time the SPI was measured. In all cases SPI was greater than $6.0 \gamma$ per cent before the end of 16 weeks, usually far earlier. In one instance, IB, after 12 weeks it was $7.9 \gamma$ per cent. Though it fell sharply to $4.0 \gamma$ per cent at the end of 15 weeks, it had returned to $6.2 \gamma$ per cent in another week and thereafter has remained elevated. This illustrates the fluctuations which were mentioned above. When $\mathrm{MJ}$ was first seen, after eight 
weeks of pregnancy, without any signs of hypothyroidism, her SPI was only $3.7 \gamma$ per cent. After ten weeks it had risen only to $4.0 \gamma$ per cent. Three weeks later, however, at the end of 13 weeks it had risen to $6.1 \gamma$ per cent. After 21 weeks it had dipped slightly to $5.6 \gamma$ per cent. Its further course has not been determined, but the patient is within six weeks of term. The woman appears to be one of those with a delayed rise. In two instances SPI was measured before pregnancy. In one, $\mathrm{RR}$, it was above $6.0 \gamma$ per cent and had not risen higher eight weeks after the last menstrual period. In the other it had risen from a prepregnancy concentration of 5.7 to $7.4 \gamma$ per cent after six weeks of pregnancy. These cases lend support to the thesis that SPI normally rises comparatively early in pregnancy to $6 \gamma$ per cent or more and remains elevated until delivery.

TABLE I

Undelivered, apparently normal pregnant women

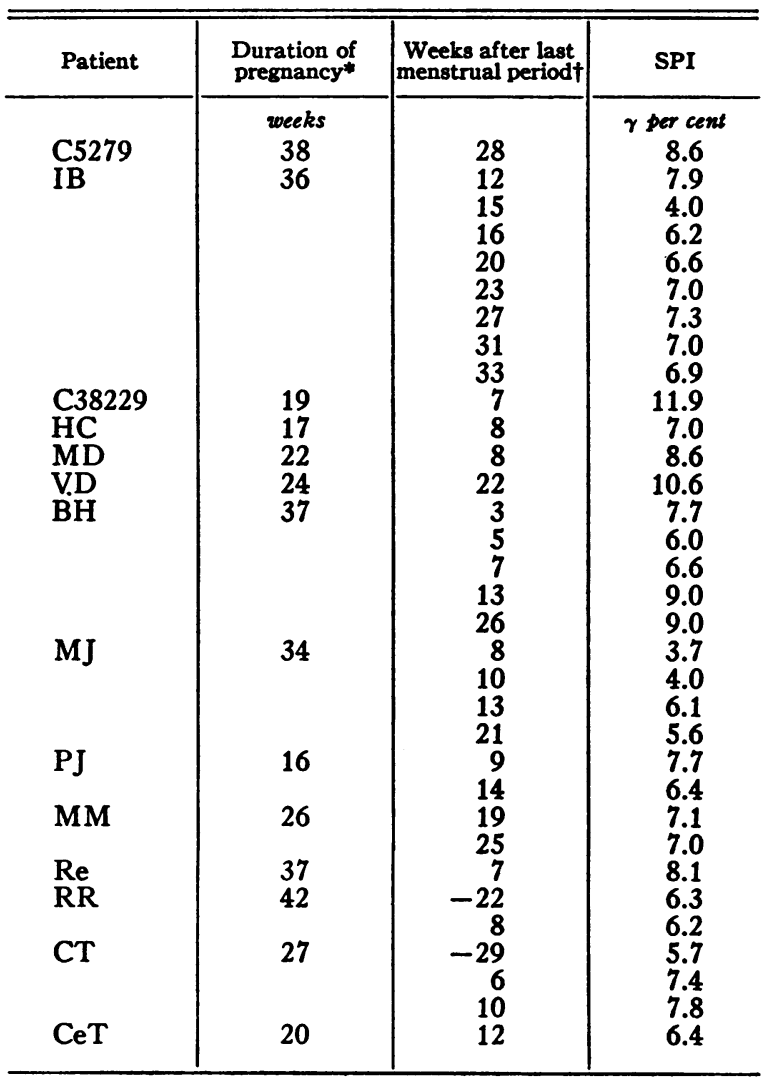

* The duration at the time the paper was written.

t A minus sign denotes that the observation was made at the indicated interval before conception.
TABLE II

Complicated pregnancies

\begin{tabular}{|c|c|c|c|}
\hline Patient & $\begin{array}{c}\text { Weeks after } \\
\text { last menstrual } \\
\text { period* }\end{array}$ & SPI & Complication \\
\hline $\begin{array}{l}\text { B73578 } \\
63694\end{array}$ & $\begin{array}{r}20 \\
8\end{array}$ & $\begin{array}{c}\gamma \text { per cent } \\
8.7 \\
9.7\end{array}$ & $\begin{array}{l}\text { Diabetes insipidus } \\
\text { Diabetes mellitus, } \\
\text { Kimmelstiel-Wilson }\end{array}$ \\
\hline $\begin{array}{l}\text { C2128 } \\
\text { C22464 }\end{array}$ & $\begin{array}{r}26 \\
40 \\
11\end{array}$ & $\begin{array}{l}7.4 \\
7.4 \\
7.5 \\
6.6\end{array}$ & $\begin{array}{l}\text { Toxemia of pregnancy } \\
\text { Multiple sclerosis }\end{array}$ \\
\hline 86295 & $p_{17}^{1}$ & $\begin{array}{l}0.0 \\
6.9\end{array}$ & $\begin{array}{l}\text { Toxemia of pregnancy, } \\
\text { thrombophlebitis }\end{array}$ \\
\hline $\begin{array}{l}\mathrm{C} 26972 \\
\mathrm{C} 15296\end{array}$ & $\begin{array}{l}40 \\
34 \\
40\end{array}$ & $\begin{array}{l}6.0 \\
4.8 \\
4.8\end{array}$ & $\begin{array}{l}\text { Toxemia of pregnancy } \\
\text { Toxemia of pregnancy }\end{array}$ \\
\hline 5911 & $\begin{array}{l}\text { a } 4 \text { years } \\
40 \\
\text { p } 1\end{array}$ & $\begin{array}{l}4.1 \\
6.0 \\
4.6\end{array}$ & Diabetes \\
\hline $\begin{array}{l}13258 \\
\text { B77955 } \\
\text { B94664 } \\
31123\end{array}$ & $\begin{array}{r}30 \\
8 \\
8 \\
8\end{array}$ & $\begin{array}{r}12.1 \\
8.4 \\
7.0 \\
7.2\end{array}$ & $\begin{array}{l}\text { Toxemia of pregnancy } \\
\text { Toxemia of pregnancy } \\
\text { Toxemia of pregnancy } \\
\text { Vascular disease }\end{array}$ \\
\hline
\end{tabular}

* a denotes that the observation was made at the indicated interval before pregnancy; $p$ denotes that the observation was made at the indicated interval after delivery.

Abnormal pregnancy. In addition to the patients with normal pregnancies, 12 pregnant women with complications of one kind or another, not involving the thyroid gland, were studied. The observations on these cases are shown in Table II. Of the 12 patients, eight had toxemias of pregnancy or vascular disease, two had diabetes, one with a Kimmelstiel-Wilson syndrome, one had diabetes insipidus and one multiple sclerosis. In spite of these complications, SPI fell in the range characteristic of pregnancy in all but one case, C15296. This patient was studied at the end of 34 weeks and again just before delivery. On both occasions SPI was $4.8 \gamma$ per cent. What it may have been earlier or later is unknown. In two instances, 63694 and C22464, pregnancy. was terminated: in one for a Kimmelstiel-Wilson syndrome, in the other for multiple sclerosis. In both SPI fell in the characteristic manner after pregnancy. In a patient with diabetes, 5911, SPI was measured before, during, and after pregnancy. The value during pregnancy was 1.9 and $1.4 \gamma$ per cent greater than the values before and after pregnancy, respectively. These complications, therefore, appear not to modify the effects of pregnancy upon SPI.

There were two patients with ectopic preg- 
nancies. One, three weeks after her last menstrual period, had an SPI of $4.0 \gamma$ per cent. Further observations could not be obtained. The second, after ten weeks of pregnancy, had an SPI of $8.3 \gamma$ per cent, which had fallen to $6.8 \gamma$ per cent 13 days after operation.

Abortions. In Table III are epitomized the records of 26 patients who aborted within the first 16 weeks of pregnancy. SPI was less than $6.0 \gamma$ per cent in 18 of the 26 . This suggests that failure of SPI to rise during the first 16 weeks is conducive to abortion. Such an inference, however, must be drawn with reservations. In some instances the serum was drawn after bleeding or cramps had begun, occasionally on the day of the abortion. Under such circumstances it is impossible to tell whether the analysis was made before or after the termination of the pregnancy. Sometimes-for example, in Cases DP and MB-the abortion definitely preceded the measurement of

TABLE III

Serum precipitable iodine of patients who aborted

\begin{tabular}{|c|c|c|c|c|c|}
\hline Patient & SPI & Weeks* & $\begin{array}{c}\text { Time of abortiont } \\
\text { p last SPI }\end{array}$ & Thyroid $\ddagger$ given & Remarks \\
\hline $\begin{array}{l}\text { DB } \\
\text { EBr } \\
\text { EKe } \\
\text { B68002 } \\
\text { DP } \\
\text { NP } \\
\text { C5510 } \\
\text { ABl } \\
\text { BH } \\
\text { MG } \\
\text { B98775 } \\
\text { DC } \\
\\
\text { RD } \\
\text { LJ } \\
\text { HR } \\
\text { EBe } \\
\text { EI } \\
\text { BK } \\
\text { LL } \\
\text { HS } \\
\text { RBa } \\
\text { MB } \\
\text { IB } \\
\text { MH } \\
\mathrm{MPo} 1 \\
\text { MPo, } \\
\text { EWi }\end{array}$ & $\begin{array}{c}\gamma \text { per cent } \\
5.8 \\
3.5 \\
4.5 \\
5.2 \\
5.6 \\
5.4 \\
6.9 \\
6.5 \\
5.2 \\
7.0 \\
8.3 \\
2.7 \\
4.7 \\
5.4 \\
4.6 \\
5.8 \\
\\
7.5 \\
7.1 \\
4.0 \\
7.0 \\
4.7 \\
7.6 \\
6.8 \\
4.7 \\
5.4 \\
7.0 \\
7.0 \\
4.3 \\
6.5 \\
5.3 \\
6.1 \\
3.3 \\
3.8 \\
7.3 \\
8.5 \\
4.6 \\
2.8 \\
4.4 \\
4.6 \\
5.2 \\
4.6 \\
\end{array}$ & 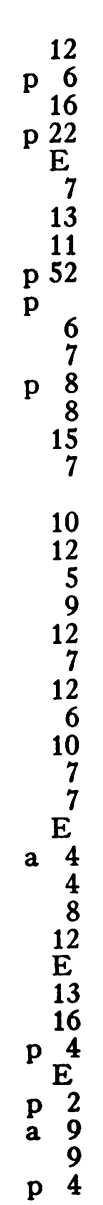 & $\begin{array}{c}1 \text { day } \\
0 \text { day } \\
0 \text { day } \\
9 \text { weeks } \\
-? \text { day } \\
? \\
-1 \text { day } \\
10 \text { weeks } \\
\pm 1 \text { day } \\
3 \text { days } \\
1 \text { day } \\
\\
1 \text { week } \\
4 \text { weeks } \\
2 \text { weeks } \\
2 \text { weeks } \\
3 \text { weeks } \\
1 \text { week } \\
1 \text { week } \\
1 \text { week } \\
\text { few days } \\
\text { few days } \\
-1 \text { day } \\
\text { few days } \\
\text { few days } \\
1 \text { day } \\
9 \text { days } \\
4 \text { weeks }\end{array}$ & $\begin{array}{l}\mathrm{T} \\
\mathrm{T} \\
\text { Th } \\
\text { Th } \\
\mathrm{T} \\
\\
\mathrm{Th} \\
0.24 \\
\text { Th } \\
0.24 \\
\text { Th } \\
0.12 \\
0.12 \\
\text { Th } \\
0.12 \\
0.03 \\
0.06 \\
0.12\end{array}$ & $\begin{array}{l}\text { Abortion just before SPI } \\
\text { May have aborted at time of first } \\
\text { SPI } \\
\text { Slight bleeding } \\
\text { ? Hypothyroid }\end{array}$ \\
\hline
\end{tabular}

* If not otherwise marked, indicates weeks after last menstrual period; a indicates weeks before conception; $\mathrm{p}$ indicates weeks after delivery. $E$ indicates early in pregnancy, the exact time being unknown.

+ A minus sign indicates that SPI was done after the abortion, 0 that it was done on the day of the abortion; ? that the precise interval is unknown.

$\ddagger T$ indicates that thyroxine was given intravenously immediately after the SPI was done. Th indicates that thyroid was given at the first sign of abortion. The daily dose of thyroid is given when the drug was administered for an appreciable time. 
SPI. In other cases, such as B68002 and AB1, the abortion occurred so long after the determination of SPI that it is impossible to relate the two. The SPI of B68002, at the end of seven weeks, was $5.4 \gamma$ per cent. It is quite impossible to assert that nine weeks later, when she aborted, it had not risen above $6.0 \gamma$ per cent. Conversely, AB1's SPI of $8.3 \gamma$ per cent at the end of six weeks may have fallen before her abortion ten weeks later. In five cases $(\mathrm{DB}, \mathrm{EBr}, \mathrm{NP}, \mathrm{RBa}$ and $\mathrm{EWi}$ ) figures for SPI before or after pregnancy are available for comparison. In every case these are distinctly different. In two, DB and EWi, the SPI was higher in pregnancy, but below $6.0 \gamma$ per cent. In a third, NP, it was $6.5 \gamma$ per cent in pregnancy. In the remaining two, $\mathrm{EBr}$ and $\mathrm{RBa}$, SPI appears to have fallen instead of rising during pregnancy. In no instance was the SPI outside of pregnancy below the normal range. In eight cases SPI was over $6.0 \gamma$ per cent. Whether or not, therefore, a low value is incompatible with continuation of pregnancy, a high value does not insure against abortion. In seven cases thyroid or thyroxine, or both, were given at the time SPI was measured, because of bleeding, without preventing the abortion. In most of these abortion followed so rapidly that the thyroid can have had little effect. It is possible that some of these patients had aborted before the thyroid or thyroxine was given. DC, for example, was given thyroxine for bleeding after the seventh week. The bleeding stopped and SPI rose and remained high under continued treatment with thyroid. At the end of the 12th week she bled again. The Ascheim-Zondek test at this time proved to be negative. It seems highly probable that she actually aborted on the earlier occasion. $\mathrm{RD}$, on the other hand, did not escape an abortion, despite the administration of enough thyroid to raise her SPI from 4.0 to $7.0 \gamma$ per cent. Whether it remained at this level is uncertain, because the dose of thyroid was reduced from 0.24 to $0.12 \mathrm{gm}$. between the second determination and abortion. Several patients were already receiving variable amounts of thyroid when SPI was first measured. In four of these EI, HS, IB, and $\mathrm{MPo}_{2}$, SPI was low in spite of the medication. In $\mathrm{MPo}_{2}$, despite $0.12 \mathrm{gm}$. of thyroid daily, SPI was lower during pregnancy, $2.8 \gamma$ per cent, than it was two weeks after abor-
TABLE IV

Patients who, having previously aborted (see Table III), had successful pregnancies

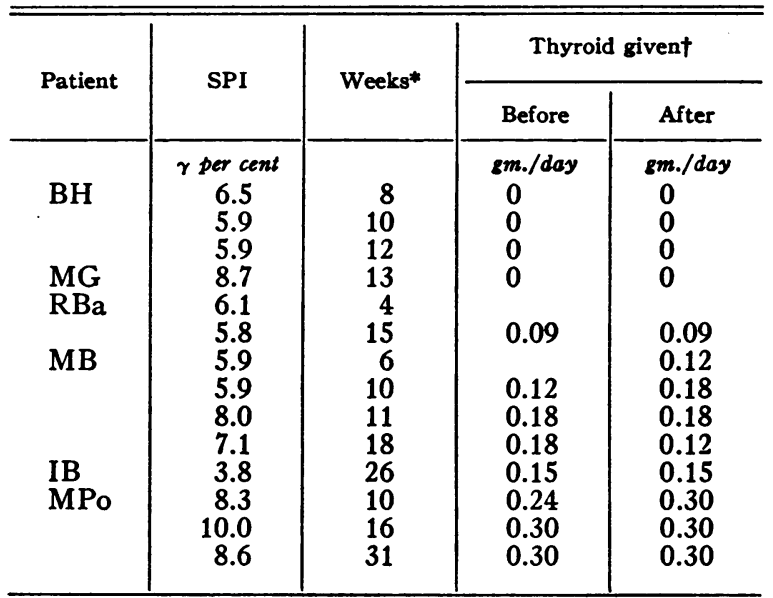

* Weeks after last menstrual period.

$\uparrow$ Before indicates that the patient was receiving thyroid before the determination of SPI. After indicates that medication was begun after the determination of SPI.

tion, $4.4 \gamma$ per cent. Although these figures suggest that low SPI conduces to abortion, they permit no definite conclusions, chiefly because only single observations are available on subjects who did not receive thyroid. It is clear that administration of thyroid after bleeding has begun will not consistently prevent abortion, even if it raises SPI above $6.0 \gamma$ per cent.

In Table IV are presented the data from six patients who, having aborted in one pregnancy, successfully carried through another to delivery. The records during the pregnancy that ended in abortion have been given in Table III. The first two, $\mathrm{BH}$ and $\mathrm{MG}$, had no complications nor special therapy during their successful pregnancies. Both had, however, far higher SPI's on the second occasions. The SPI of $\mathrm{BH}$ after seven weeks of her earlier pregnancy was $2.7 \gamma$ per cent; in her successful pregnancy it was $6.5 \gamma$ per cent at the end of eight weeks and subsequent figures after ten and 12 weeks were $5.9 \gamma$ per cent. MG had SPI's of 5.4 and $8.7 \gamma$ per cent, respectively. The comparison in this case is not so precise as it is in $\mathrm{BH}$, because the analysis in the early pregnancy was made after eight weeks, while in the successful pregnancy it was made after 13 weeks. In both instances during the earlier pregnancy, after bleeding had begun, administration of thyroxine and thyroid failed to 
prevent abortion. The remaining four cases were treated with thyroid. Among these, $\mathrm{RBa}$ and MPo had higher SPI's in their successful pregnancies. The remainder were already receiving thyroid or were given thyroid when SPI was first measured. In every case but one, initial SPI's were greater than 5.0, and subsequent values never lower than $5.8 \gamma$ per cent. The exception, IB, is quite unique. The only determination, made after 26 weeks, was $3.8 \gamma$ per cent, when the patient was receiving daily $0.15 \mathrm{gm}$. of thyroid.

Forty-eight women, without evidence of hypothyroidism, successfully completed 51 pregnancies while receiving thyroid substance. This treatment was instituted for such diverse reasons that in the majority of cases it is impossible to determine whether or not it prevented abortions

TABLE $\mathrm{V}$

Patients with threatened abortions

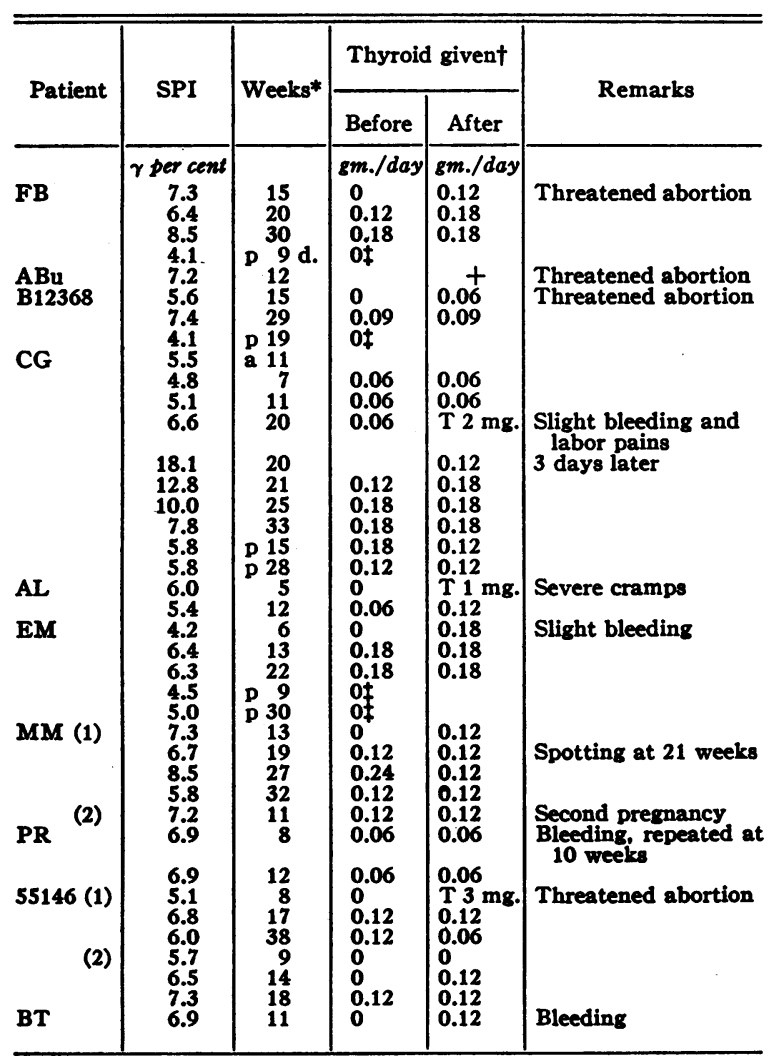

* a indicates before pregnancy, $p$ indicates after delivery. $\dagger$ Before indicates that the patient was already receiving thyroid. After indicates that thyroid was begun after the measurement of SPI.

$\ddagger$ No thyroid given after delivery. or contributed in any way to the well-being of the mother or fetus. Frequently it was begun before the first observation of SPI or even before the onset of pregnancy because of a history of previous abortions or infertility. So commonly is thyroid administered in pregnancy for various reasons without objective criteria of deficient thyroid function that its beneficial effect is almost impossible to evaluate. In ten of the 57 pregnancies abortion was threatened at one time or another, but pregnancy continued to term. These are presented in Table V. Bleeding or cramps occurred in eight of these during the first 16 weeks. Of these eight only four had SPI's of $6.0 \gamma$ per cent or less. In the other four SPI varied from 6.9 to $7.3 \gamma$ per cent. Thyroid was given to all eight immediately. Obviously SPI greater than $6.0 \gamma$ per cent does not confer protection against bleeding or cramps. But just as obviously it is impossible to assert that these patients would have aborted if thyroid had not been given. In two instances bleeding occurred after 20 and 21 weeks, respectively. In one the SPI had risen gradually from $4.8 \gamma$ per cent at seven weeks to $6.6 \gamma$ per cent at 20 weeks. The patient had received $0.06 \mathrm{gm}$. of thyroid daily up to this time, when bleeding began. She was immediately given $2 \mathrm{mg}$. of thyroxine intravenously. Three days later SPI was $18.1 \gamma$ per cent. The bleeding stopped. At the end of four more days when SPI had fallen to $12.8 \gamma$ per cent, she was given a continuing dose of $0.12 \mathrm{gm}$. daily, which was increased to $0.18 \mathrm{gm}$. at the end of 25 weeks. On this dose SPI fell to $7.8 \gamma$ per cent at the end of 33 weeks and to $5.8 \gamma$ per cent after delivery. The SPI of the second patient was $7.3 \gamma$ per cent at the end of 13 weeks, but six weeks later had dropped to $6.7 \gamma$ per cent in spite of the fact that she had meanwhile been given $0.12 \mathrm{gm}$. of thyroid daily. At the end of 21 weeks she began to bleed. Whether SPI had fallen further was not ascertained. The dose of thyroid was at once increased to $0.24 \mathrm{gm}$. Six weeks later, when SPI was $8.5 \gamma$ per cent, the dose was reduced to 0.12 gm. again because the patient complained of nervousness. With this one exception, possibly transient, at a late stage of pregnancy, after 16 weeks all values were $6.0 \gamma$ per cent or higher. In four of the subjects postpartum values were below $6.0 \gamma$ per cent, but within the normal range. 
In these respects, therefore, whether administration of thyroid contributed to the prevention of abortion or not, SPI followed the course characteristic of normal pregnancy.

Effects of administration of dried thyroid or thyroxine. In Table VI are presented the rec-

TABLE VI

Patients who received thyroid because of low SPI

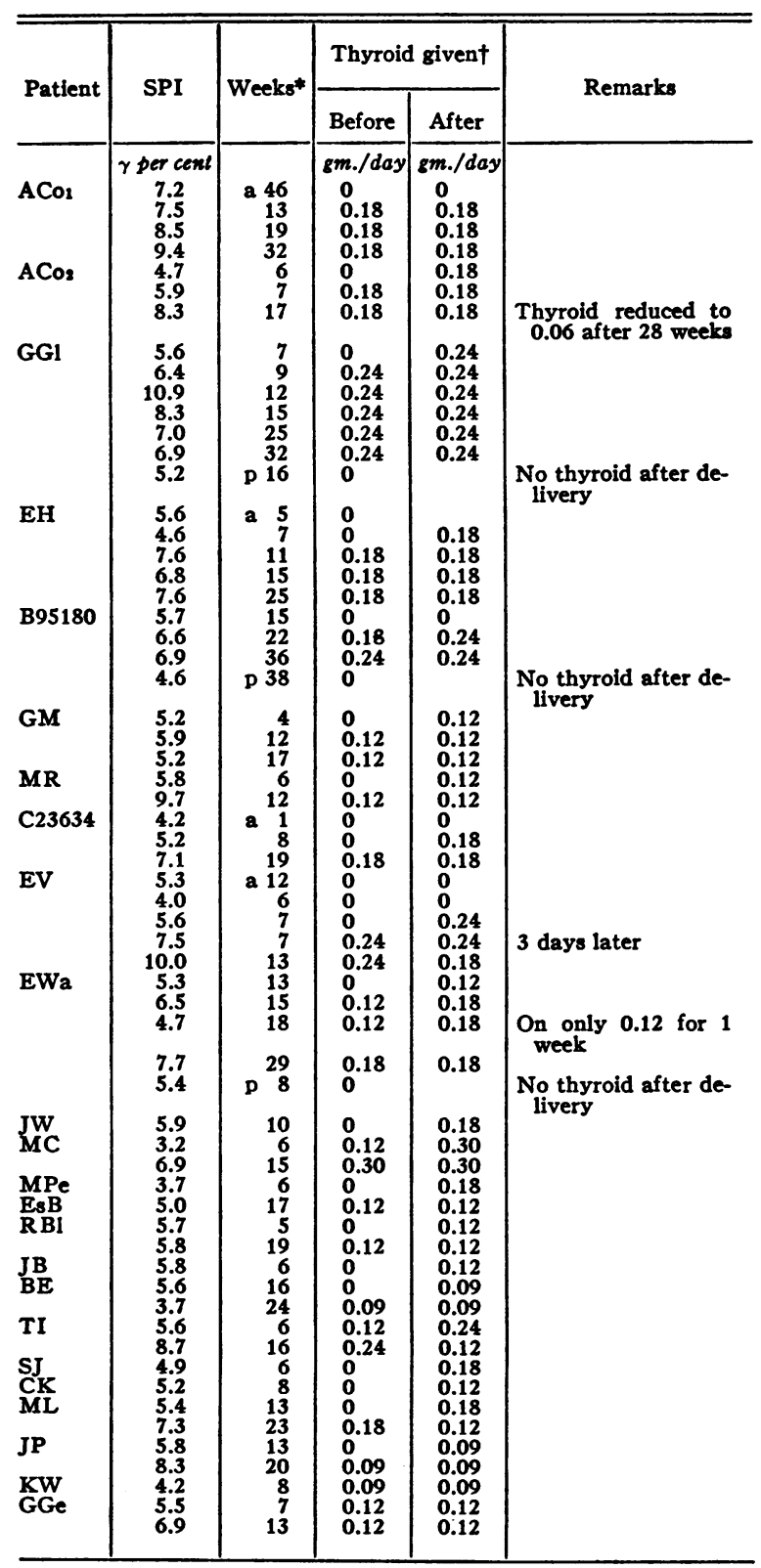

* $a$ indicates before pregnancy, $p$ indicates after delivery. $\dagger$ Before indicates that the patient was already receiving thyroid. After indicates that thyroid was begun after the measurement of SPI. ords of 23 women who were given thyroid or larger doses of thyroid specifically because SPI was low in the early stages of pregnancy. All delivered at term. In the majority of those who had repeated examinations, SPI rose above $6.0 \gamma$ per cent. The number of prolonged studies is, however, small. In four instances (GM, EWa, EsB and $\mathrm{RB} 1$ ), SPI was less than $6.0 \gamma$ per cent between 16 and 20 weeks in spite of thyroid. Two of these probably represent transitory drops: GM to $5.2 \gamma$ per cent at 17 weeks, and EWa to $4.7 \gamma$ per cent at 18 weeks. The latter had an SPI of $7.7 \gamma$ per cent at 29 weeks. In this instance SPI fell from $5.3 \gamma$ per cent at 13 weeks to $4.7 \gamma$ per cent at 18 weeks in spite of $0.18 \mathrm{gm}$. of thyroid daily. A single observation on EsB at 17 weeks, while she was receiving $0.12 \mathrm{gm}$. of thyroid daily, was $5.0 \gamma$ per cent. The remaining determination on $\mathrm{RBl}$, at 19 weeks, while she was receiving $0.12 \mathrm{gm}$. of thyroid, was $5.8 \gamma$ per cent, practically indistinguishable from $6.0 \gamma$ per cent. In one patient, BE, SPI of $5.6 \gamma$ per cent at 16 weeks, without medication, fell to $3.7 \gamma$ per cent at 24 weeks on $0.12 \mathrm{gm}$. of thyroid. This suggests that she disposed of exogenous thyroid with great facility. Such sporadic low values in the later stages of pregnancy have been noted earlier. In most instances SPI appears to be highly responsive to the administration of thyroid. It is not, however, possible in most of these to distinguish the effects of thyroid from the influence of pregnancy itself. The SPI of ACo, for example, before pregnancy, when she was not receiving thyroid, was $7.2 \gamma$ per cent. In her first pregnancy, for no clear reason, she was given $0.18 \mathrm{gm}$. of thyroid at nine weeks. Without any change of this dose, SPI was successively 7.5, 8.5, and $9.4 \gamma$ per cent at 13,19 , and 32 weeks respectively. This patient is remarkable in certain other respects. During the course of the year succeeding her delivery, without thyroid, she had an abortion. In a subsequent pregnancy, which is recorded in the Table, her SPI at six weeks was only $4.7 \gamma$ per cent. On $0.18 \mathrm{gm}$. of thyroid it rose to $5.9 \gamma$ per cent after a week and to $8.3 \gamma$ per cent at 17 weeks, approximately the same as its concentration at the same stage of her first pregnancy. GGl was given $0.24 \mathrm{gm}$. of thyroid daily at seven weeks, when her SPI was $5.6 \gamma$ per cent. Without any change of dose, the SPI rose 
TABLE VII

Patients who received thyroid and delivered normally, although no SPI lower than $6.0 \gamma$ per cent was observed

\begin{tabular}{|c|c|c|c|c|c|}
\hline \multirow{2}{*}{ Patient } & \multirow{2}{*}{ SPI } & \multirow{2}{*}{ Weeks* } & \multicolumn{2}{|c|}{ Thyroid givent } & \multirow{2}{*}{ Remarks } \\
\hline & & & Before & After & \\
\hline \multirow{4}{*}{$\begin{array}{l}\text { JK } \\
\text { HL }\end{array}$} & $\gamma$ per cent & & $g m . / d a y$ & gm./day & \multirow{13}{*}{$\begin{array}{c}0.24 \text { begun after } 14 \\
\text { weeks }\end{array}$} \\
\hline & & 18 & & 0.25 & \\
\hline & $\begin{array}{l}0.8 \\
7.6\end{array}$ & $\begin{array}{l}23 \\
19 \\
26\end{array}$ & 0.25 & 0.25 & \\
\hline & $\begin{array}{l}5.0 \\
4.8\end{array}$ & $\begin{array}{l}31 \\
32\end{array}$ & $\begin{array}{l}0.12 \\
0.12\end{array}$ & $\begin{array}{l}0.12 \\
0.12\end{array}$ & \\
\hline DM & $\begin{array}{l}6.0 \\
7.2 \\
6.4\end{array}$ & 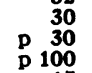 & $\begin{array}{l}0.06 \\
0.06 \\
0.06\end{array}$ & $\begin{array}{l}0.06 \\
0.06\end{array}$ & \\
\hline HP & $\begin{array}{l}5.1 \\
6.3 \\
9.9 \\
5.8\end{array}$ & $\begin{array}{r}17 \\
7 \\
9 \\
20\end{array}$ & $\begin{array}{l}0 \\
0.18 \\
0.18\end{array}$ & $\begin{array}{l}0.18 \\
0.18 \\
0.18\end{array}$ & \\
\hline CP & $\begin{array}{l}6.0 \\
5.9\end{array}$ & $\begin{array}{l}11 \\
16\end{array}$ & 0.24 & $\begin{array}{l}0.12 \\
0.24\end{array}$ & \\
\hline HT & $\begin{array}{l}6.3 \\
6.1 \\
7.1 \\
6.6\end{array}$ & $\begin{array}{r}20 \\
9 \\
12 \\
16\end{array}$ & $\begin{array}{l}0.24 \\
0 \\
0.18 \\
0.18\end{array}$ & $\begin{array}{l}0.24 \\
0.18 \\
0.18 \\
0.18\end{array}$ & \\
\hline C24722 & $\begin{array}{l}0.0 \\
7.3\end{array}$ & $\begin{array}{l}10 \\
30\end{array}$ & 0.18 & 0.18 & \\
\hline EKo & $\begin{array}{l}6.4 \\
6.3\end{array}$ & $\begin{array}{r}37 \\
6\end{array}$ & 0.18 & $\begin{array}{l}0.18 \\
0.06\end{array}$ & \\
\hline MN & $\begin{array}{l}9.2 \\
4.9 \\
6.5 \\
7.8 \\
8.3 \\
6.1 \\
5.5\end{array}$ & $\begin{array}{r}18 \\
\mathrm{a} 124 \\
17 \\
20 \\
27 \\
27 \\
10 \\
13 \\
\end{array}$ & $\begin{array}{l}0.18 \\
0.06 \\
0.06 \\
0.12 \\
0.12 \\
0.12 \\
0.12\end{array}$ & $\begin{array}{l}0.18 \\
0.06 \\
0.12 \\
0.12 \\
0.09 \\
0.12 \\
0.24\end{array}$ & \\
\hline $\begin{array}{l}\text { RR } \\
\text { HB } \\
\text { LE } \\
\text { MPl }\end{array}$ & $\begin{array}{l}6.3 \\
6.2 \\
7.3 \\
7.3 \\
6.6 \\
6.4\end{array}$ & $\begin{array}{r}22 \\
\mathbf{2} \\
12 \\
12 \\
\\
\\
\\
\\
8 \\
19\end{array}$ & $\begin{array}{l}0.12 \\
0.06 \\
0 \\
0 \\
0.09\end{array}$ & $\begin{array}{l}0.18 \\
0.06 \\
0.06 \\
0.09 \\
0.03\end{array}$ & \\
\hline DS & 6.7 & 13 & & 0.06 & \\
\hline
\end{tabular}

* If not otherwise marked, indicates weeks after last menstrual period; a indicates weeks before conception; $p$ indicates weeks after delivery.

$\dagger$ Before indicates that the patient was already receiving thyroid. After indicates that thyroid was begun after the measurement of SPI.

to a peak of $10.9 \gamma$ per cent at 12 weeks and thereafter gradually declined to $6.9 \gamma$ per cent at 32 weeks. After delivery, when thyroid had been discontinued, it fell still further, to $5.2 \gamma$ per cent. This suggests that, although thyroid may accelerate the initial rise of SPI, thereafter, on a constant dose, SPI follows the course usual in pregnancy. In spite of the fact that doses of from 0.18 to $0.30 \mathrm{gm}$. of thyroid were given to these subjects over long periods, SPI did not exceed the concentrations ordinarily encountered in pregnancy nor were symptoms or signs of hyperthyroidism encountered. This may denote that the pregnant woman is tolerant of the thyroid hormone or able to dispose of it with unusual facility. It must be recognized, however, that a proportion of normal women have a similar tolerance (10, 11).
If, as other evidence suggests, failure of SPI to rise is incompatible with the continuation of pregnancy, the data of Table VI suggest that administration of thyroid in generous amounts when SPI is low may prevent abortion. This would imply that the increment of SPI in pregnancy is composed of thyroid hormone. To verify this it is necessary, however, to prove more definitely that abortion is a regular consequence of a persistent low SPI. This requires the study of a larger number of untreated subjects in the early weeks of pregnancy.

Fifteen women who delivered normally were given thyroid in spite of the fact that their SPI's were $6.0 \gamma$ per cent or higher at the first observations during pregnancy, usually because of histories of previous infertility or abortions. The data from these cases are presented in Table VII. In no instance did the thyroid drive SPI above the normal range for pregnancy. In two, in fact, SPI fell after the administration of thyroid. In HL the low values were observed in the last trimester of pregnancy. In this case thyroid was not given until the end of 27 weeks. In HP, after rising from 6.3 to $9.9 \gamma$ per cent between seven and nine weeks on $0.18 \mathrm{gm}$. of thyroid, SPI dropped to $5.8 \gamma$ per cent at the end of 20 weeks. Its subsequent course is unknown.

In both these last series shown in Tables VI

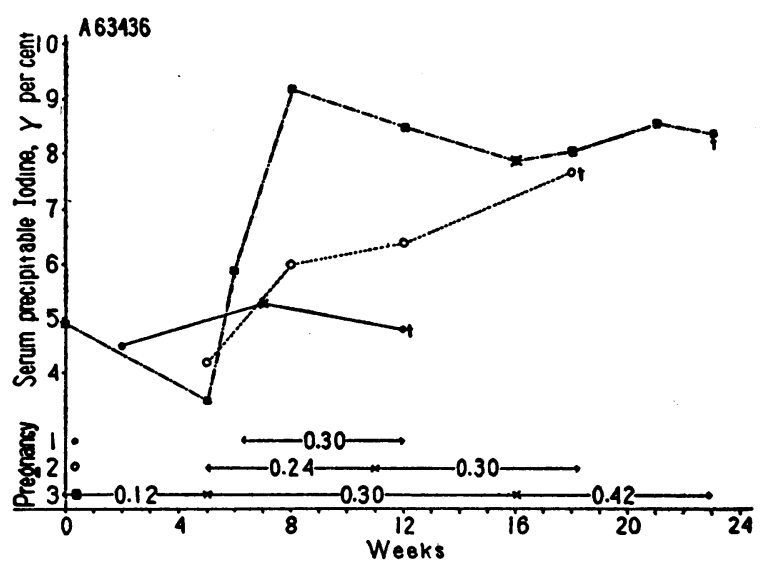

Fig. 2. The Course of SPI of a Subject in Three Pregnancies That Ended in Abortion

The daily dose of thyroid, in grams, given during each pregnancy, together with the duration of its administration, is shown by the figures and arrows below the curves. Crosses indicate bleeding or cramps; daggers represent abortion. 
and VII, as' in previous series, SPI before and after pregnancy, when it was measured, lay within the normal nonpregnant range.

That thyroid may not be successful in preventing abortion, even if it is given in large doses before any signs or symptoms appear, is illustrated by the woman whose record is illustrated in Figure 2. In her first pregnancy, at two weeks and seven weeks SPI's were 4.5 and $5.3 \gamma$ per cent, respectively. At this time, because of bleeding, she was given $0.30 \mathrm{gm}$. of thyroid daily. In spite of this she aborted and curettage was necessary at 12 weeks. Three months later she again became pregnant. After five weeks, because SPI was only $4.2 \gamma$ per cent, she was given $0.24 \mathrm{gm}$. of thyroid. At eight weeks SPI had risen to $6.0 \gamma$ per cent. Two weeks later the dose of thyroid was raised to $0.30 \mathrm{gm}$. Although SPI was $7.7 \gamma$ per cent at 18 weeks, she again aborted. Three months later, without thyroid, SPI was $4.9 \gamma$ per cent, a normal value. Nevertheless, she was given $0.12 \mathrm{gm}$. of thyroid daily. Her last menstrual period occurred two days later. At the end of five weks SPI was only $3.5 \gamma$ per cent, although the dose of thyroid had been increased to $0.24 \mathrm{gm}$. three days earlier. It was immediately raised to $0.30 \mathrm{gm}$. In another two weeks SPI was $9.2 \gamma$ per cent. In spite of the fact that it did not fall below $8 \gamma$ per cent, uterine contractions began at 16 weeks. These diminished after the dose of thyroid was increased to $0.42 \mathrm{gm}$., but she aborted after 23 weeks. In this case the rise of SPI in every pregnancy was delayed. In fact, in every instance it was lower than the only value obtained in the nonpregnant state. This was within normal limits, an indication that the subject had no thyroid deficiency. Nevertheless, large doses were required to raise SPI to characteristic pregnancy values. Even when thyroid was begun before pregnancy and relatively early elevation of SPI was achieved, abortion was not prevented. As the intensity of thyroid therapy was increased and as it was initiated at an earlier date, there was a suggestion that pregnancy was prolonged. In this case there appears to be some inherent obstacle to the conduct of normal pregnancy that is associated with low SPI. This can be ameliorated, but not abolished, by administration of enough thyroid at an early date to raise SPI to concentrations appropriate for pregnancy.
TABLE VIII

Premature deliveries

\begin{tabular}{|c|c|c|c|c|c|}
\hline \multirow{2}{*}{ Patient } & \multirow{2}{*}{ SPI } & \multirow{2}{*}{ Weeks* } & \multicolumn{2}{|c|}{ Thyroid givent } & \multirow{2}{*}{ Remarks } \\
\hline & & & Before & After & \\
\hline $\mathbf{K A}$ & $\begin{array}{c}\gamma \text { per cent } \\
8.8\end{array}$ & 25 & $\begin{array}{c}\mathrm{gm} . / \mathrm{day} \\
0.15\end{array}$ & $\begin{array}{c}\mathrm{gm} . / \mathrm{day} \\
0\end{array}$ & $\begin{array}{l}\text { Spotting for } 6 \text { days; } \\
\text { delivery } 2 \text { days after } \\
\text { SPI. }\end{array}$ \\
\hline 19373 & 6.5 & 17 & $\mathbf{0}$ & $\mathbf{0}$ & $\begin{array}{l}\text { Slight bleeding } 4 \text { weeks } \\
\text { earlier; delivery at } 25 \\
\text { weeks. }\end{array}$ \\
\hline $\begin{array}{l}\text { VH } \\
\text { B59643 } \\
\text { MRo }\end{array}$ & $\begin{array}{l}5.1 \\
8.2 \\
7.7 \\
9.9\end{array}$ & $\begin{array}{r}6 \\
12 \\
22 \\
16\end{array}$ & $\begin{array}{l}0.06 \\
0.21 \\
0 \\
0\end{array}$ & $\begin{array}{l}0.21 \\
0.21 \\
0 \\
0\end{array}$ & $\begin{array}{l}\text { Delivery at } 36 \text { weeks } \\
\text { Delivery at } 35 \text { weeks } \\
\text { Delivery at } 36 \text { weeks }\end{array}$ \\
\hline
\end{tabular}

* Weeks after last menstrual period.

$\dagger$ Before indicates that the patient was already receiving thyroid. After indicates that thyroid was begun after the measurement of SPI.

Similar conditions may obtain in those subjects reported above who aborted in spite of normal SPI.

Premature deliveries. Attention has been called frequently to occasional low values occurring late in pregnancy. It has been impossible to attach any significance to these. Furthermore, to date no relation has been discovered between "premature" deliveries in the latter months of pregnancy and SPI. The data on this point are, however, necessarily scanty. Five patients who received the diagnosis of premature delivery are presented in Table VIII. The first two do not properly belong in this category because both delivered at 25 weeks. The first, KA, just before delivery, on $0.15 \mathrm{gm}$. of thyroid daily had an SPI of $8.8 \gamma$ per cent. The second, 19373, at 13 weeks bled slightly; but at 17 weeks had not aborted and had an SPI of $6.5 \gamma$ per cent. She went into labor, however, and delivered at 25 weeks. The remaining three patients delivered at 35 or 36 weeks. One of them, VH, was given $0.06 \mathrm{gm}$. of thyroid before pregnancy because her SPI was only $3.8 \gamma$ per cent, a low normal figure. At six weeks, because SPI had risen only to $5.1 \gamma$ per cent, the dose of thyroid was increased to 0.21 gm. daily. The SPI at 12 weeks had risen to $8.2 \gamma$ per cent. Although the thyroid was continued, she had a premature delivery after 36 weeks. The SPI's of the remaining two appear to have risen to proper pregnancy concentrations. Their pregnancies were uneventful until their deliveries at 35 and 36 weeks respectively. Neither received thyroid. It is impossible in any 


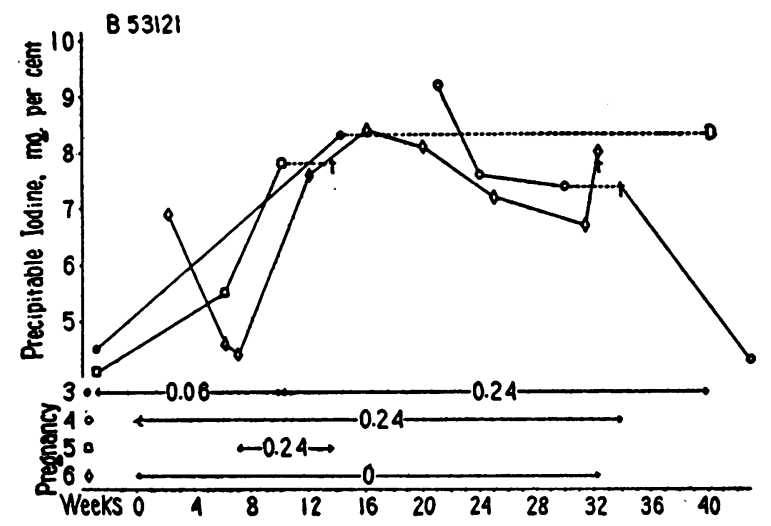

Fig. 3. The Course of SPI During Four Pregnancies of a Subject with a Tendency to Premature DeLIVERY

The general construction of the chart is similar to that of Figure 2. D represents normal delivery.

of these cases to be certain that SPI did not fall later in the course of pregnancy.

One patient, whose record is illustrated in Figure 3 , merits especial consideration. At the age of 22 , because of a basal metabolism of -23 , she was given $0.0125 \mathrm{gm}$. of thyroid daily. In 1939, when her basal metabolism was found to be -12 , she was given $0.06 \mathrm{gm}$. of thyroid daily. On neither occasion did she have symptoms of hypothyroidism. In November, 1942, her right tube was removed for a tubal pregnancy. In February, 1946, she had an abortion at three months. July 22,1946 , while on $0.06 \mathrm{gm}$. of thyroid daily, her SPI was $4.5 \gamma$ per cent. October 24 she became pregnant. Shortly after this the dose of thyroid was increased to $0.24 \mathrm{gm}$. daily. She had an uncomplicated pregnancy, except for slight bleeding in the first months at the times of her menstrual periods, and was delivered on July 23, 1947, at term, of a normal child. On November 10 of that year she again became pregnant. Thyroid 0.24 gm./day was begun on December 27. Again she bled slightly in the first months at the time of her normal menstrual periods; but otherwise her pregnancy proceeded normally until July 4, 1948, when she went into labor and was delivered of a premature child who died two days later. Thyroid medication was discontinued after delivery. SPI's, 38 and 93 days after delivery, were 4.3 and $4.1 \gamma$ per cent, respectively. February 23, 1949, she again became pregnant. After six weeks her SPI was $5.5 \gamma$ per cent. She was again given 0.24 gm. of thyroid daily. Four weeks later her SPI was $7.8 \gamma$ per cent. Nevertheless she had a spontaneous abortion at the end of 13 weeks. On July 27 she once more became pregnant. On this occasion no thyroid was given. SPI was $6.9 \gamma$ per cent only two weeks after her last menstrual period. Although it fell to 4.6 and $4.4 \gamma$ per cent at six and seven weeks, it rose after this spontaneously and remained well above $6.0 \gamma$ per cent until the end of 32 weeks when she bled profusely. Despite administration of $2 \mathrm{mg}$. of thyroxine intravenously, she was delivered of a dead fetus within 24 hours, with evidence of premature separation of the placenta. From the values of SPI when she was neither pregnant nor receiving thyroid, as well as the absence of symptoms and signs, the patient was evidently not hypothyroid. There is no evidence that administration of thyroid altered the course of her pregnancies. The fact that one pregnancy went to term while she was receiving thyroid seems to be purely adventitious. Without thyroid, the last, her sixth pregnancy, proceeded quite as long as did the fourth in which she received thyroid.

\section{DISCUSSION}

That SPI rises during pregnancy appears to have been established. This rise is attended by no clinical evidence of excessive activity of the thyroid gland. It occurs long before the increase of basal metabolism that accompanies pregnancy. The latter also presumably denotes no increased activity of the thyroid, but seems rather to be related to the need for extra oxygen created by the enlargement of the uterus and the growth of the fetus.

The almost complete absence of SPI's below $6.0 \gamma$ per cent after 16 weeks suggests that concentrations above this are, in normal persons, necessary for the successful completion of pregnancy. At the left of Figure 1 the limits of variation of SPI in various conditions are defined. It is evident that in a group of nonpregnant women of this size the majority of points would lie between 4 and $6 \gamma$ per cent, an area that is almost empty, and that there would be only an occasional spot above $7 \gamma$ per cent, which is the most thickly populated area of the figure. In the period before 12 or 16 weeks there are more points in the normal range. If all pregnant women were in- 
cluded, not only those who completed pregnancy without medication, the area between 4 and $6 \gamma$ per cent in the first weeks of pregnancy would be fuller. From the paucity of points below $6 \gamma$ per cent after 16 weeks, the fact that the SPI of nonpregnant women most frequently lies in this area, and the greater frequency of such points in the earlier weeks of pregnancy, it may be inferred that before the end of this period SPI regularly attains a concentration of $6 \gamma$ per cent or more and that when it fails to rise to this level abortion occurs.

In the patients who aborted and those who received thyroid substances, as in the normal pregnancies, there is the same tendency for SPI in pregnancy to lie above $6.0 \gamma$ per cent after 16 as pregnancy advances to 16 weeks. SPI, therefore, in a considerable number of women, remains low in the early weeks of pregnancy. Some of the later points below $6 \gamma$ per cent represent transient fluctuations. However, the concentration 6.0 was selected somewhat arbitrarily because the great majority of observations lay above this concentration. It would be surprising indeed if there were not some overlap in the zone of differentiation. The two extremely low figures represent single observations on two patients. What the SPI may have been at other times in the course of pregnancy is unknown. On the whole the data support the earlier hypothesis that if pregnancy is to be completed, SPI is not consistently below about $6.0 \gamma$ per cent after preg-

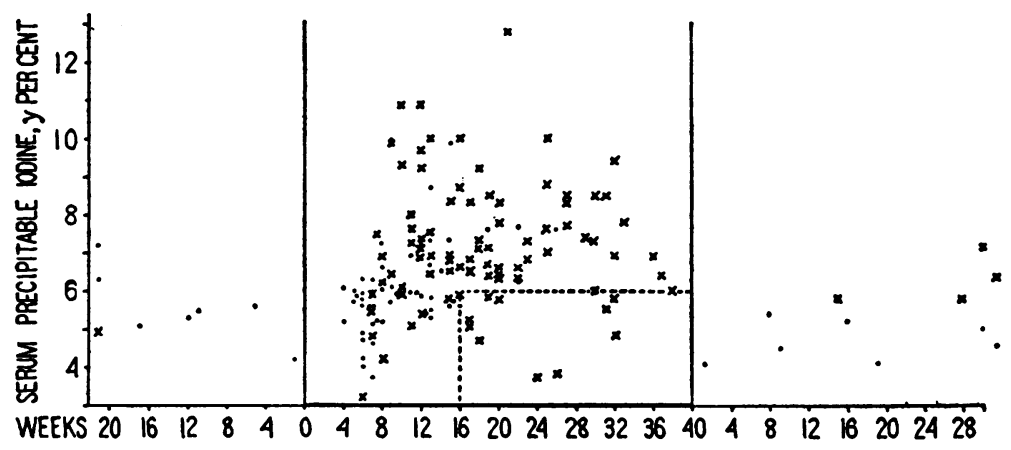

Fig. 4. The SPI of All Subjects Who Received Thyroid and Successfully Completed Pregnancy

Dots indicate that the subject had not received thyroid, crosses that she had received thyroid before the observation. The period of pregnancy is defined by the vertical lines. The area to the left represents time before, that to the right time after, pregnancy.

weeks. This is best illustrated in Figure 4 which includes all observations on patients who were delivered at term. A cross indicates that the subject was receiving thyroid, a dot that she was taking no medication. The paucity of points in the area below $6.0 \gamma$ per cent after 16 weeks is again evident. Of the total number of observations only ten are found in this area. Of these, five are greater than $5.0 \gamma$ per cent.

There is, however, in contrast to the series of normal pregnancies reported in the preceding paper, a larger aggregation of values below $6 \gamma$ per cent in the early weeks of pregnancy. This would be still greater if the observations in Table III from the subjects who aborted were included. The incidence of low points also seems to diminish nancy has proceeded approximately 16 weeks. This would mean that SPI regularly achieves this level in the course of the first 16 weeks in successful pregnancies. This suggests, but does not necessarily imply, that failure of SPI to rise in this period conduces to abortion. Definitive proof that this is the case must depend upon the intensive study of a large group of subjects during early pregnancy without medication.

In the small series thus far collected, early miscarriage appears to be more common in those with low SPI. An SPI above $6.0 \gamma$ per cent, however, obviously does not preclude abortion. If failure of SPI to rise does predetermine abortion, the question arises whether there is a critical time and a critical concentration. Sometimes 
SPI exceeds $6.0 \gamma$ per cent as early as the diagnosis of pregnancy can be established. In other cases it remains below this concentration until the period of 16 weeks is almost completed. The majority of miscarriages occur earlier than this. If low SPI is correlated with the cause, rather than the incidence, of miscarriage, why do some subjects tolerate low values longer than others do? Are those who do miscarry inherently incapable of raising their SPI's or would their SPI's eventually rise if they escaped miscarriage?

Failure of SPI to rise in those that miscarry may be an indication that there is a defect in the ovum or its implantation of such a kind that the stimulus that causes SPI to rise is lacking. In those in which SPI rises late, but abortion is avoided, this stimulus may be only partly lacking, or the defect may lie not in a deficient stimulus, but in a deficient or delayed reaction of the mechanism responsible for the rise of SPI, presumably the secretory activity of the thyroid gland or the utilization of the thyroid hormone, or both. In this case SPI would be little more than a symbol. Miscarriages would be associated with low SPI, but the latter would not necessarily determine a miscarriage. Such a hypothesis seems to be consistent with most of the facts presented. It gains some support from the cases in which the patient who miscarried in one pregnancy with low SPI had a subsequent successful pregnancy when SPI rose early (cases $\mathrm{BH}$ and MG, Tables III and IV). It might partly explain the consistent failure to complete pregnancies displayed by A63436 (Figure 2). It would not, however, account so well for the relative absence of low values after 16 weeks or the apparent prolongation of pregnancy by thyroid in A63436.

This hypothesis would relegate the elevation of SPI and the thyroid hormone to a derivative or adventitious position. Alternatively, completion of pregnancy may depend on the proper reactivity of the mechanism which causes SPI to rise, presumably increased secretory activity of the thyroid gland, with diminished or increased utilization of thyroid hormone. If the first hypothesis is correct, the common practice of administering thyroid to prevent abortion, which originated on a purely empirical basis, would be of no value. These two hypotheses are not, of course, mutually exclusive. It may be that both stimulus and re- activity of the thyroid gland must be adequate. The present study is intended in part to throw some light on these questions.

It is clear from the data of Table III that the administration of thyroid, or even thyroxine, in massive doses, will not regularly prevent abortion after symptoms have begun. In most instances, however, there can be no assurance that abortion was not already an accomplished fact before the thyroid or thyroxine was given. The generally higher values of SPI in the successful pregnancies of Table IV, as contrasted with those in the abortive pregnancies of the same individuals in Table III, suggest that a high SPI is advantageous and that administration of thyroid tends to raise SPI. The patients in Table $\mathrm{V}$ might be cited as more direct evidence of the beneficial effect of thyroid. In this group completion of abortion may have been prevented by timely administration of thyroid. In five of the ten pregnancies, medication was followed by a distinct rise of SPI. In three of the five, SPI at the onset of cramps or bleeding was lower than $6 \gamma$ per cent. The total number of cases is, however, small and the number of controls who, under similar circumstances, did not receive thyroid is smaller. In Tables VI and VII is a goodly array of women who, having received thyroid, completed pregnancy successfully without symptoms of miscarriage at any time. The greater proportion of these (those in Table VI) were given thyroid because SPI was low. In most of those in which further observations were made, SPI rose in response to the medication, but repeated observations were all too few and again adequate controls are lacking. The data on the whole suggest, but certainly do not prove, that administration of thyroid prevents abortion.

Attention has been called to the incidence of abortions with SPI above $6 \gamma$ per cent. If low SPI does promote abortion, these cases can not be summarily dismissed as belonging to a different category. In normal pregnancy some women carry higher SPI than others. This may be a necessary provision. In only one of the patients of this series, in addition to A63436 (Figure 2), did abortion or threatened abortion occur when SPI was $7.5 \gamma$ per cent or higher. It may be more than a coincidence that the points below $6 \gamma$ per cent after 16 weeks in Figure 4 are all 
derived from patients who were receiving thyroid. If the increment of SPI in pregnancy is composed of thyroid hormone, its significance still remains to be elucidated. It could mean diminished utilization of hormone, though this seems highly unlikely. It is generally held, from morphological studies, that secretory activity of the thyroid is increased and, as a corollary, that this is a response to an increased demand for the hormone to meet increased utilization. An increased supply would then be the prime necessity. With the administration of exogenous thyroid the tissues might be able to derive the necessary hormone from the circulation by more efficient extraction with a lower concentration in the serum.

Much of this discussion and the data on which it is based tend to pose rather than to answer questions as to the clinical value and significance of SPI in pregnancy. The data may, however, throw some light on the nature of the increment in pregnancy. Values of SPI as high as those encountered in pregnancy are regularly associated with symptoms of hyperthyroidism in nonpregnant women. This seems to denote either that the pregnant woman tolerates a greater concentration of hormone in her serum or that the increment is not composed of thyroid hormone. In many of the cases in this series, SPI was rapidly raised by administration of thyroid or thyroxine to levels characteristic of hyperthyroidism without appearance of symptoms. Presumably these increments of iodine were hormonal. Pregnancy does, therefore, appear to confer a tolerance for circulating thyroid hormone. In a few instances in which SPI was suddenly raised to unusually high concentrations it tended to decline to more moderate concentrations as pregnancy advanced. Whether the endogenous supply was reduced, utilization accelerated, or removal by other channels increased, it is impossible as yet to say. It is noteworthy that on the whole, regardless of the dose of thyroid, the concentration of SPI, with the exception of the temporary shoots mentioned above, tended to establish itself in the range characteristic of pregnancy.

This tolerance appears to differ somewhat from that displayed by nonpregnant women, in which the concentration of SPI does not rise, or, after a preliminary rise, recedes to the normal range
(10). In most of the present series in which SPI was measured postpartum, thyroid was discontinued after delivery. In the two cases in which it was continued, it was found to be in the normal nonpregnant range. In one it fell after delivery. This strengthens the impression that SPI is sustained by pregnancy. Whether the increment of SPI is, like the greater proportion of the normal SPI, composed of thyroid hormone cannot be decided from these studies. It does behave like the thyroid hormone in attaching itself to the serum proteins. Furthermore, it is extracted by butanol $(12,13)$.

\section{CONCLUSIONS}

The serum precipitable iodine has been determined on one or more occasions during pregnancy in 46 women without complications or signs of overactivity or underactivity of the thyroid gland who delivered at term. In only three instances was SPI observed below $6.0 \gamma$ per cent after 16 weeks of pregnancy. In nine patients with pregnancies complicated by conditions other than abnormal activity of the thyroid, SPI with one exception lay at the same high levels. This is also true of 14 patients still undelivered but with apparently normal pregnancies, well advanced. In those patients studied before and after pregnancy, SPI is found to rise early in pregnancy and to fall shortly after delivery.

The precipitable iodine of serum (SPI) has been measured in a series of euthyroid pregnant women who aborted or who received thyroid substance to prevent abortion. There is some evidence that if SPI does not rise above about $6 \gamma$ per cent during the first 16 weeks, pregnancy is unlikely to proceed to term and that abortion is more common in those women whose SPI's do not rise relatively early in pregnancy. Administration of generous amounts of thyroid substance accelerates the rise of SPI. The cases reported suggest that, if thyroid is given early enough, it may diminish the tendency to abortion. A larger body of controls is required to establish these points.

If thyroid is given to the pregnant woman, the curve of SPI tends to follow a course similar to that of the untreated pregnant woman. The implications of this fact with respect to the nature 
and significance of the increment of SPI in pregnancy are discussed.

\section{ACKNOWLEDGMENTS}

Thanks must be given to Drs. Irving Friedman and Milton S. Godfried for their generosity in permitting the use of data derived from their patients, and in making their records available; and to Dr. Herbert Thoms, Professor of Obstetrics and Gynecology, and his staff for their cooperation.

\section{REFERENCES}

1. Heinemann, M., Johnson, C. E., and Man, E. B., Serum precipitable iodine concentrations during pregnancy. J. Clin. Invest., 1948, 27, 91.

2. Man, E. B., and Gildea, E. F., A modification of the Stoddard and Drury titrimetric method for the determination of the fatty acids in blood serum. J. Biol. Chem., 1932, 99, 43.

3. Man, E. B., and Gildea, E. F., Notes on the extraction and saponification of lipids from blood and blood serum. J. Biol. Chem., 1937, 122, 77.

4. Man, E. B., and Peters, J. P., Gravimetric determination of serum cholesterol adapted to the Man and Gildea fatty acid method, with a note on the estimation of lipoid phosphorus. J. Biol. Chem., 1933, 101, 685.
5. Man, E. B., A note on the stability and quantitative determination of phosphatides. J. Biol. Chem., 1937, 117, 183.

6. Bogdanovitch, S. B., and Man, E. B., The effects of castration, theelin, testosterone and antuitrin-S on the lipoids of blood, liver and muscle of guinea pigs. Am. J. Physiol., 1938, 122, 73.

7. Man, E. B., Smirnow, A. E., Gildea, E. F., and Peters, J. P., Serum iodine fractions in hyperthyroidism. J. Clin. Invest., 1942, 21, 773.

8. Kydd, D. M., Man, E. B., and Peters, J. P., Concentration of precipitable iodine in the serum. J. Clin. Invest., 1950, 29, 1033.

9. Danowski, T. S., Hedenburg, S., and Greenman, J. H., The constancy of the serum precipitable or protein-bound iodine in healthy adults. J. Clin. Endocrinol., 1949, 9, 768.

10. Winkler, A. W., Lavietes, P. H., Robbins, C. L., and Man, E. B., Tolerance to oral thyroid and reaction to intravenous thyroxine in subjects without myxedema. J. Clin. Invest., 1943, 22, 535.

11. Riggs, D. S., Man, E. B., and Winkler, A. W., Serum iodine of euthyroid subjects treated with desiccated thyroid. J. Clin. Invest., 1945, 24, 722.

12. Danowski, T. S., Gow, R. C., Mateer, F. M., Everhart, W. C., Johnston, S. Y., and Greenman, J. $\mathrm{H}$., Increases in serum thyroxin during uncomplicated pregnancy. Proc. Soc. Exper. Biol. \& Med., 1950, 74, 323.

13. Man, E. B., Unpublished studies. 